\title{
Commentary
}

\section{Lessons learned in infection prevention for Ebola virus disease and the coronavirus disease 2019 (COVID-19) pandemic_-Principles underlying prevention}

\author{
Erica S. Shenoy MD, $\mathrm{PhD}^{1,2,3}$ (1) and David J. Weber MD, MPH ${ }^{4,5}$ \\ ${ }^{1}$ Infection Control Unit, Massachusetts General Hospital, Boston, Massachusetts, ${ }^{2}$ Division of Infectious Diseases, Massachusetts General Hospital, Boston, \\ Massachusetts, ${ }^{3}$ Harvard Medical School, Boston, Massachusetts, ${ }^{4}$ Division of Infectious Disease, School of Medicine, University of North Carolina at Chapel Hill, \\ Chapel Hill, North Carolina and ${ }^{5}$ Department of Hospital Epidemiology, UNC Medical Center, Chapel Hill, North Carolina
}

Delivery of care to patients with highly communicable diseases balances the potential risk of transmission from the patient-tohealthcare personnel (HCP) with the risks to the patient of delayed or reduced access to needed interventions. The risk of transmission to HCP depends on many factors described by the chain of transmission (Fig. 1), including the establishment of a reservoir (human, animal, inanimate environment), exit of the infectious agent from the reservoir and survival in the environment, with transmission by direct or indirect contact, droplet, airborne modes or combinations of these modes, and finally entry of the infectious agent via a portal of entry to a susceptible host at an inoculum sufficient to establish infection. Efforts to prevent transmission in healthcare settings - among patients, visitors, and $\mathrm{HCP}$ - are all aimed at interrupting the chain of transmission. These efforts include, in addition to correct and consistent use of personal protective equipment (PPE) plus rapid institution of appropriate isolation precautions as indicated by the mode of transmission, multiple other interventions that minimize the risk of nosocomial transmission. These measures are often framed as part of the hierarchy of controls applied to HCP safety, but they also have applications for reducing overall risk of transmission to patients and visitors. ${ }^{1}$

In this issue of Infection Control and Hospital Epidemiology, DiLorenzo et $\mathrm{al}^{2}$ report on a survey of policies of Ebola treatment centers with respect to provision (planned or actual) of critical care interventions for patients with viral hemorrhagic fevers (VHFs) such as Ebola virus disease (EVD). ${ }^{2}$ The researchers distributed a 58-item survey to 82 Ebola treatment centers between January 2020 and March 2020, and report on the responses of 17 institutions of which fewer than half had experience caring for patients with VHFs or persons under investigation (PUIs). They used the survey to query institutions on policies in 9 critical care areas: renal replacement therapy, endotracheal intubation and mechanical ventilation, extracorporeal membrane oxygenation, chest compressions, pharmacological cardioversion, electrical cardioversion, defibrillation, cricothyrorotomy, and code status. The survey further inquired about the extent to which staff safety, lack of

Author for correspondence: Erica S. Shenoy, E-mail: eshenoy@mgh.harvard.edu Cite this article: Shenoy ES and Weber DJ. (2021). Lessons learned in infection prevention for Ebola virus disease and the coronavirus disease 2019 (COVID-19) pandemic_-Principles underlying prevention. Infection Control \& Hospital Epidemiology, 42: 457-460, https://doi.org/10.1017/ice.2020.1427

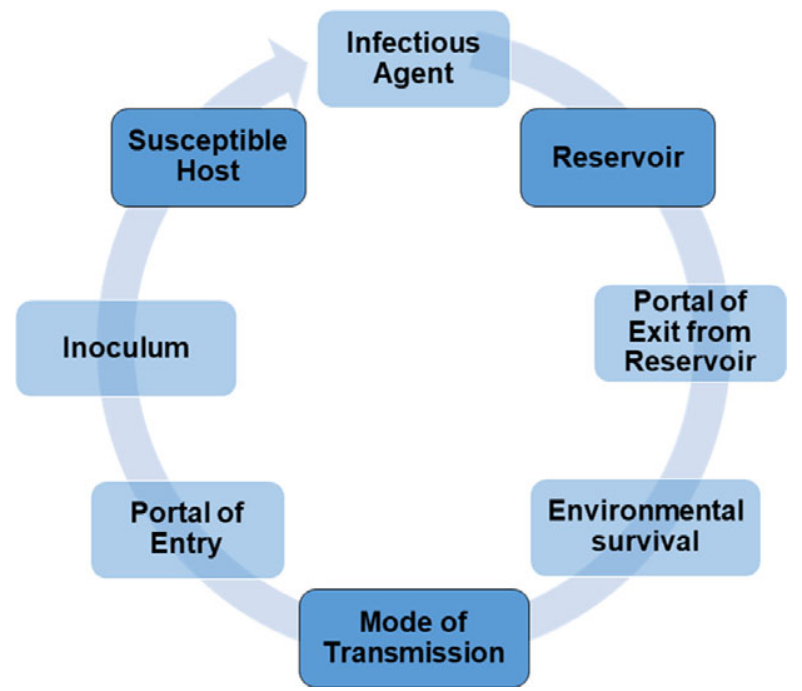

Fig. 1. The chain of transmission. Transmission from one individual to another requires completion of each step in the chain of transmission. Beginning with an infectious agent in a reservoir (eg, human, animal, or inanimate object/surface), the infectious agent must exit the reservoir through portal of exit; survive in the environment; and be transmitted by contact, droplet, or airborne routes (or a combination thereof); and enter as susceptible host through a portal of entry (eg, eyes, nose, mouth, wound) at an inoculum sufficient to establish infection.

appropriate technology, lack of clinical guidelines, clinical futility, and limitations of the environment of care, influenced policies regarding provision of care. Most respondents had policies regarding replacement, endotracheal intubutation and mechanical ventilation, and chest compressions, although applications of each varied by patient-level factors. For other interventions, fewer respondents reported having policies, and types of patients (PUI vs confirmed VHF) to whom it would be offered varied. Among the factors influencing decision regarding offering care to either PUIs or confirmed VHF patients, staff safety and clinical futility were reported to influence decisions "somewhat" or "greatly" for most respondents whereas lack of appropriate technology, guidelines, or physical limitations in the environment of care either did not limit care (or minimally limited care) according to most respondents.

() The Author(s), 2021. Published by Cambridge University Press on behalf of The Society for Healthcare Epidemiology of America. This is an Open Access article, distributed under the terms of the Creative Commons Attribution licence (http://creativecommons.org/licenses/by/4.0/), which permits unrestricted re-use, distribution, and reproduction in any medium, provided the original work is properly cited. 
Table 1. Comparison of Pathogens Primarily Transmitted by Contact with Body Fluids (eg, Ebola virus) Versus Respiratory Droplets and Droplet Nuclei (eg, SARS-CoV-2)

\begin{tabular}{|c|c|c|}
\hline Variable & Ebola Virus & SARS-CoV-2 \\
\hline \multicolumn{3}{|l|}{ Microbiology } \\
\hline Year identified & 1976 & 2019 \\
\hline Family & Filaviridae & Coronaviridae \\
\hline Genome & RNA & RNA \\
\hline Coat & Enveloped & Enveloped \\
\hline \multicolumn{3}{|l|}{ Epidemiology } \\
\hline Prevalence & Repeated outbreaks & Pandemic \\
\hline Reservoir & Bats & $\begin{array}{l}\text { Bats; research ongoing to identify additional } \\
\text { potential reservoirs }\end{array}$ \\
\hline Intermediate host & Primates and other animals & None demonstrated \\
\hline Primary mode of transmission & Direct Contact: Contact with infectious body fluids & Respiratory droplets \\
\hline Other modes of transmission & $\begin{array}{l}\text { Indirect contact (ie, contaminated surfaces, devices), sexual, blood } \\
\text { transfusion }\end{array}$ & $\begin{array}{l}\text { Direct and indirect contact } \\
\text { (ie, contaminated surfaces, devices) }\end{array}$ \\
\hline Basic reproductive rate $\left(R_{0}\right)$ & $1.5-2.0^{23}$ & $1.8-3.6^{24}$ \\
\hline $\begin{array}{l}\text { Asymptomatic and presymptomatic } \\
\text { transmission }\end{array}$ & No & Yes \\
\hline Incubation period & 6-12 d (range, 2-21) & $2-14 d$ \\
\hline Case fatality rate & 50\% (range, 25\%-90\%) & $\sim 15 \%$ among hospitalized patients \\
\hline Treatment & $\begin{array}{l}\text { Monoclonal antibody combination (atoltivimab, maftivimab, and } \\
\text { odesivimab-ebgn) }\end{array}$ & Remdesivir, bamlanivimab \\
\hline \multicolumn{3}{|l|}{ Infection prevention } \\
\hline $\begin{array}{l}\text { Nosocomial transmission involving } \\
\mathrm{HCP} \text { (HCP-to-HCP, HCP-to-patient, } \\
\text { patient-to-HCP) }\end{array}$ & Yes & Yes \\
\hline Laboratory biosafety level & BSL-4 & $\begin{array}{l}\text { BSL-2 (routine diagnostic testing); BSL-3 } \\
\text { (virus isolation in cell culture) }\end{array}$ \\
\hline Survival on surfaces & Hours to a few days & Hours to a few days \\
\hline Antiseptic & $60 \%-90 \%$ alcohol-based product & $60 \%-90 \%$ alcohol-based product \\
\hline Disinfectant & EPA, emerging virus claim (List "N") & $\begin{array}{l}\text { EPA, emerging virus claim } \\
\text { (List "N") }\end{array}$ \\
\hline $\begin{array}{l}\text { Special handling of used linens, } \\
\text { patient waste }\end{array}$ & Yes & No \\
\hline PPE worn by HCP (CDC) & $\begin{array}{l}\text { 1. Single-use (disposable) fluid-resistant gown that extends to at } \\
\text { least mid-calf or single-use (disposable) fluid-resistant coveralls } \\
\text { without integrated hood } \\
\text { 2. Single-use (disposable) full face shield } \\
\text { 3. Single-use (disposable) face mask } \\
\text { 4. Single-use (disposable) gloves with extended cuffs. Two pairs of } \\
\text { gloves should be worn. At a minimum, outer gloves should have } \\
\text { extended cuffs. }{ }^{25}\end{array}$ & $\begin{array}{l}\text { 1. N95 respirator (or equivalent or higher- } \\
\text { level respirator) or facemask (if a respira- } \\
\text { tor is not available) } \\
\text { 2. Eye protection (ie, goggles or a face shield } \\
\text { that covers the front and sides of the face) } \\
\text { 3. Single use (disposable), clean, nonsterile } \\
\text { gloves } \\
\text { 4. Single use (disposable) isolation gown or } \\
\text { cloth gown. }\end{array}$ \\
\hline Pre-exposure prophylaxis & Vaccine & Vaccine \\
\hline Postexposure prophylaxis & None approved for postexposure prophylaxis & None \\
\hline
\end{tabular}

Note. BSL, biosafety level; EPA, US Environmental Protection Agency; HCP, healthcare personnel.

The fact that HCP safety has such a prominent impact on decisions to offer particular types of care is not unique to VHFs; it has been a concern raised in the provision of care to patients infected with SARS-CoV-2. Some prominent differences between the two pathogens underly the potential risk of nosocomial acquisition to HCP. Specifically, the primary modes of transmission (EVD primarily through contact and SARS-CoV-2 primarily through droplets), and the ability of individuals to transmit infection while asymptomatic or presymptomatic (not considered likely with EVD but prominent with SARS-CoV-2) are key aspects that inform the infection prevention strategies (Table 1).

The data available for VHFs and SARS-CoV-2, however, demonstrate that the major risks to HCP stem from failure to identify patients at entrance to a healthcare facility as possibly infected and to isolate them appropriately, from failure to utilize personal protective equipment (PPE) correctly especially during donning and 
doffing, and from inadequate PPE due to shortages. These same challenges have been present during the COVID-19 pandemic. Additionally, HCP-to-HCP spread of SARS-CoV-2 has been linked to lapses in masking and distancing when masks are removed to eat or drink (eg, in break rooms and at nursing stations) and when physical distancing is not maintained. Acquistion by HCP has then led in some cases to transmission to patients with propagation of transmission. ${ }^{3}$

The primary intervention to reduce risk of nosocomial transmission relies on early identification of PUIs and intiation of isolation. For both $\mathrm{EVD}^{4}$ and SARS-CoV- $2,{ }^{5-8}$ failures at this critical juncture have resulted in exposures to HCP and transmission events. Although self-contamination and cross contamination are concerns with SARS-CoV-2 and careful doffing and use of hand hygiene must be emphasized, transmission directly attributable to doffing failure has not been documented. One SARS-CoV-2 serological study failed to identify an association between positive serology and care of patients with COVID-19; however, these researchers did note a strong association of living in a household with an individual with suspected or confirmed SARS-CoV-2 infection. ${ }^{9}$ Another serological study of HCP noted lower prevalence of SARS-CoV-2 antibodies among HCP who reported consistent use of a face mask when caring for patients. ${ }^{10}$

In contrast, due to contact with blood and body fluids as the primary mode of transmission with EVD, self- and cross-contamination is a priority concern to the extent that extensive training in the use of PPE, careful selection of PPE components and order of doffing, close attention to the design of the physical space where doffing occurs is warranted, and the implementation of a trained observer is recommended by the CDC to ensure each HCP doffs correctly and that instances of possible contamination are identified during the process and mitigated. ${ }^{11-15}$ Use of dedicated HCP with who have trained and exercised in the use of PPE for Ebola is recommended both to the high-risk aspect of doffing PPE while avoiding self-contamination and cross contamination, as well as the fact that the PPE used for EVD and other viral hemorrhagic fevers is not used routinely in most healthcare settings. Adjunctive approaches, such as techniques to visualize contamination ${ }^{16}$ and the use of ultraviolet disinfection of PPE, ${ }^{17}$ have been shown to reduce the transmission risk to HCP. In some settings with EVD, and worldwide with SARS-CoV-2 due to the large-scale global nature of the pandemic with resultant interruption of supply chain, PPE shortages have led to strategies that have included extended use, reuse of PPE following disinfection or decontamination, and use of alternative PPE components that have not been certified, as well as lack of adequate PPE. ${ }^{18} \mathrm{HCP}$-to-HCP transmission of VHFs has been reported. ${ }^{19,20}$ HCP-to-HCP of SARS-CoV-2 infection has been well documented via droplet spread, in part because it can be transmitted from asymptomatic, presymptomatic, and pauci-symptomatic individuals, especially in settings where masking is not present (eg, break rooms). ${ }^{21,22}$ Transmission events are not restricted to HCP interactions in the workplace and are more likely to occur during external social activities where masking compliance between HCP may be reduced.

DiLorenzo et $\mathrm{al}^{2}$ demonstrated that HCP safety in provision of critical care to EVD PUIs is informed by assessment of risk of potential for patient-to-HCP transmission. Similar concerns have underscored the COVID-19 pandemic and highlight the importance of multifaceted approaches to interrupting the chain of transmission. Differences between the 2 pathogens, however, specifically the primary modes of transmission and the role of asymptomatic and presymptomatic transmission, underscore differences observed in the overall risk of patient-to-HCP transmission.

Financial support. Dr. Shenoy reports support from the Assistant Secretary for Preparedness and Response (ASPR) to the MGH Regional Emerging Special Pathogens Treatment Center (grant no. 6U3REP150548-05-08).

Conflicts of interest. All authors report no conflicts of interest relevant to this article.

\section{References}

1. National Institute for Occupational Safety and Health. Hierarchy of Controls. Centers for Disease Control and Prevention website. https:// www.cdc.gov/niosh/topics/hierarchy/default.html. Published 2015. Accessed January 8, 2021.

2. DiLorenzo MA BC, Herstein JJ, Evans L, Lowe JJ, Gibbs SG, Bhadelia N. Institutional Policies and readiness in management of critical illness in among patients with viral hemorrhagic fever. Infect Control Hospital Epidemiol 2020.

3. Healthcare facilities: managing operations during the COVID-19 pandemic. Centers for Disease Control and Prevention website. https://www.cdc.gov/ coronavirus/2019-ncov/hcp/guidance-hcf.html. Published 2020. Accessed January 8, 2021.

4. Anderson-Fletcher E, Vera D, Abbott J. The Texas Health Presbyterian Hospital Ebola crisis: a perfect storm of human errors, system failures, and lack of mindfulness. Agency for Healthcare and Research Quality website. https://psnet.ahrq.gov/issue/texas-health-presbyterian-hospitalebola-crisis-perfect-storm-human-errors-system-failures. Published 2015. Accessed January 8, 2021.

5. Bays DJ, Nguyen MH, Cohen SH, et al. Investigation of nosocomial SARSCoV-2 transmission from two patients to health care workers identifies close contact but not airborne transmission events. Infect Control Hospital Epidemiol 2020. doi: 10.1017/ice.2020.321.

6. Baker MA, Rhee C, Fiumara K, et al. COVID-19 infections among HCWs exposed to a patient with a delayed diagnosis of COVID-19. Infect Control Hospital Epidemiol 2020;41:1075-1076.

7. Heinzerling A, Stuckey MJ, Scheuer T, et al. Transmission of COVID-19 to healthcare personnel during exposures to a hospitalized patient-Solano County, California, February 2020. Morb Mortal Wkly Rep 2020;69: 472-476.

8. Ng K, Poon BH, Kiat Puar TH, et al. COVID-19 and the risk to healthcare workers: a case report. Ann Intern Med 2020;172:766-767.

9. Steensels D, Oris E, Coninx L, et al. Hospital-wide SARS-CoV-2 antibody screening in 3056 staff in a tertiary center in Belgium. JAMA 2020;324: 195-197.

10. Self WH, Tenforde MW, Stubblefield WB, et al. Seroprevalence of SARSCoV-2 Among frontline health care personnel in a multistate hospital network - 13 academic medical centers, April-June 2020. Morb Mortal Wkly Rep 2020;69:1221-1226.

11. Guidance on personal protective equipment (PPE) to be used by healthcare workers during management of patients with confirmed Ebola or persons under investigation (PUIs) for Ebola who are clinically unstable or have bleeding, vomiting, or diarrhea in US hospitals, including procedures for donning and doffing PPE. Centers for Disease Control and Prevention website. https://www.cdc.gov/vhf/ebola/healthcare-us/ppe/guidance.html. Published 2015. Accessed January 8, 2021.

12. Rock C, Cosgrove SE, Keller SC, et al. Using a human factors engineering approach to improve patient room cleaning and disinfection. Infect Control Hospital Epidemiol 2016;37:1502-1506.

13. Reddy SC, Valderrama AL, Kuhar DT. Improving the use of personal protective equipment: applying lessons learned. Clin Infect Dis 2019;69 suppl 3: S165-S170.

14. DuBose JR, Matić Z, Sala MFW, et al. Design strategies to improve healthcare worker safety in biocontainment units: learning from Ebola preparedness. Infect Control Hospital Epidemiol 2018;39: 961-967. 
15. Wong MF, Matić Z, Campiglia GC, et al. Design strategies for biocontainment units to reduce risk during doffing of high-level personal protective equipment. Clin Infect Dis 2019;69 suppl 3:S241-S247.

16. Tomas ME, Cadnum JL, Mana TS, et al. Utility of a novel reflective marker visualized by flash photography for assessment of personnel contamination during removal of personal protective equipment. Infect Control Hospital Epidemiol 2016;37:711-713.

17. Tomas ME, Cadnum JL, Jencson A, Donskey CJ. The Ebola disinfection booth: evaluation of an enclosed ultraviolet light booth for disinfection of contaminated personal protective equipment prior to removal. Infect Control Hospital Epidemiol 2015;36:1226-1228.

18. Strategies for optimizing personal protective equipment (PPE) supplies. Centers for Disease Control and Prevention website. https://www.cdc. gov/coronavirus/2019-ncov/hcp/ppe-strategy/index.html. Published 2020. Accessed January 8, 2021.

19. Burney MI, Ghafoor A, Saleen M, Webb PA, Casals J. Nosocomial outbreak of viral hemorrhagic fever caused by Crimean hemorrhagic fever-Congo virus in Pakistan, January 1976. Am J Trop Med Hyg 1980;29:941-947.

20. Ftika L, Maltezou HC. Viral haemorrhagic fevers in healthcare settings. J Hosp Infect 2013;83:185-192.
21. Çelebi G, Pişkin N, Çelik Bekleviç A, et al. Specific risk factors for SARSCoV-2 transmission among health care workers in a university hospital. Am J Infect Control 2020;48:1225-1230.

22. Ellsworth M, Chang M, Ostrosky-Zeichner L. Mind the gap: the hospital breakroom. Am J Infect Control 2020;48:1285.

23. Khan A, Naveed M, Dur-E-Ahmad M, Imran M. Estimating the basic reproductive ratio for the Ebola outbreak in Liberia and Sierra Leone. Infect Dis Poverty 2015;4:13.

24. Petersen E, Koopmans M, Go U, et al. Comparing SARS-CoV-2 with SARSCoV and influenza pandemics. Lancet Infect Dis 2020;20:e238-e244.

25. For US healthcare settings: donning and doffing personal protective equipment (PPE) for evaluating persons under investigation (PUIs) for Ebola who are clinically stable and do not have bleeding, vomiting, or diarrhea. Centers for Disease Control and Prevention website. https://www.cdc.gov/ vhf/ebola/healthcare-us/ppe/guidance-clinically-stable-puis.html. Published 2018. Accessed January 8, 2021.

26. Interim infection prevention and control recommendations for healthcare personnel during the coronavirus disease 2019 (COVID-19) pandemic. Centers for Disease Control and Prevention website. https://www.cdc.gov/ coronavirus/2019-ncov/hcp/infection-control-recommendations.html. Published 2020. Accessed January 8, 2021. 